\title{
Before and After the Sin Tax Law: Perceived Changes in Tertiary Government Hospitals by Inpatients and Healthcare Workers
}

\author{
Gideon D. Lasco, ${ }^{1}$ Jose Eduardo DL. Duya, ${ }^{2}$ Josephine H. Sanchez ${ }^{3}$ and Antonio L. Dans ${ }^{3}$ \\ ${ }^{1}$ Department of Anthropology, University of the Philippines Diliman \\ ${ }^{2}$ Section of Cardiology, Department of Medicine, College of Medicine and Philippine General Hospital, University of the Philippines Manila \\ ${ }^{3}$ Section of Adult Medicine, Department of Medicine, College of Medicine and Philippine General Hospital, University of the Philippines Manila
}

\begin{abstract}
Background. The implementation of the "Sin Tax Law" (RA 10351) in 2013 has increased revenues for healthcare in the Philippines. What changes have taken place in government hospitals since the passage of the law? This qualitative study sought to answer this question by presenting perspectives from patients, doctors, and nurses.

Methods. Four focus group discussions (FGDs) and eight semi-structured interviews (SSIs) were conducted among patients, doctors, and nurses in two tertiary government hospitals in Metro Manila, Philippines.

Results. Significant changes noted by study participants over the past several years included increased financial assistance for patients as well as improvements in health services and continuity of care. However, their narratives underscored shortcomings in human resources and facilities, raising questions of 'absorptive capacity'.

Conclusion. Given that the Sin Tax Law was the main policy intervention to which the changes reported by study participants can be attributed, the study provides a strong case for a continuation - if not expansion - of the Law, with the recommendation that increased health revenue should also translate to greater support for healthcare workers and enhanced health facilities. As these insights may be overlooked by traditional metrics, the study also recommends that policymakers consider qualitative studies in evaluating the efficacy of health care reforms.
\end{abstract}

Key Words: Health financing, patient perspectives, tobacco taxation, universal healthcare, Philippines

\section{INTRODUCTION}

In 2012 the Philippine Congress passed Republic Act 10351, which introduced higher excise rates for alcohol and tobacco products in the Philippines. ${ }^{1}$ Popularly known as the "Sin Tax Law", this piece of legislation was envisioned by the government as one of the vehicles that could usher Kalusugang Pangkalahatan or universal healthcare (UHC). ${ }^{2}$ The net revenues generated from this tax were earmarked towards the enrolment of more patients in the national health insurance company (80\%) and the provision of financial assistance through the Department of Health (20\%), after deducting 15\% towards supporting tobacco farmers' move to alternative livelihoods. ${ }^{3}$

Following WHO recommendations, the law imposed a specific form of excise tax on the products (e.g., per piece,

Corresponding author: Gideon D. Lasco, MD, PhD Department of Anthropology

University of the Philippines Diliman

Diliman, Quezon City 1101, Philippines

Telephone: +632981 8500 local 2114

Email: gideonlasco@gmail.com per pack, per proof liter) to discourage consumption and generate revenues that are more predictable and easier to administer. ${ }^{4}$ In enacting it, the Philippines became one of the first countries in the Southeast Asian region to earmark 'sin taxes' specifically for health expenditures. ${ }^{5}$ 
Three years after it was implemented, Sin Tax revenues have significantly boosted government finances for healthrelated spending. In 2015, of the PHP 86.97 billion (US\$ 1.7 billion) budget of the Department of Health (DOH), $38 \%$ or PHP 33.74 billion (US $\$ 0.67$ billion) were from the Sin Tax revenues. ${ }^{3}$ In addition to funding $\mathrm{DOH}$ programs, PHP 2.72 billion (US\$54 million) was also earmarked for a "medical assistance program" that aims to provide direct financial assistance to patients, especially indigents. The Sin Tax revenues are additionally credited for increasing enrolment in PhilHealth, the national health insurance scheme (World Health Organisation 2017). ${ }^{6}$

In light of these policy and fiscal changes, it is insightful to look at the changes in government hospitals years after the passage of the Sin Tax Law, from the perspective of its intended beneficiaries. Did patients feel an actual improvement in health service delivery? Did doctors and nurses notice an improvement in health facilities, and do they perceive any changes in their workload, as well as in the ways in which the patients engage with them?

This paper sought to answer these questions by drawing from the narratives and insights of people in two public tertiary hospitals in Metro Manila, Philippines, either as recipients or providers of health care. Taking an inductive approach inspired by grounded theory ${ }^{7}$, this qualitative research aimed to elicit perspectives of healthcare workers $(\mathrm{HCWs})$ and patients regarding the perceived changes in their hospital over the past several years. It also strove to identify barriers to better health care provisioning in tertiary government hospitals and provide recommendations on how to improve health service delivery.

Although the changes noted by the study participants cannot be solely attributed to the Sin Tax Law, it can nonetheless be regarded, at the very least, as a significant factor as the only recent legislative measure that has demonstrably transformed the health sector in terms of financing and population coverage. As a World Bank report notes: "The reform scaled up health care financing, nearly doubling the Department of Health's (DOH) budget in its first year of implementation and financing the extension of fully subsidized health insurance to the poorest 40 percent of the population.." ${ }^{8}$ Lessons learned from this exercise can thus be useful not just for the Philippines but for lowand middle-income countries that are implementing or contemplating earmarked health revenues from excise taxes.

\section{METHODS}

Four focus group discussions (FGDs) each involving 7-9 participants and eight semi-structured interviews (SSIs) were conducted from November 2016 to January 2017 involving nurses (years of service range from 6-25 years), doctors (residents and fellows from various departments), patients (with chronic conditions), and watchers in two public tertiary public hospitals in Metro Manila, with
1,500- and 300-bed capacities, respectively (anonymized as "Hospital A" and "Hospital B"). A total of 42 participants were engaged in the study, with details summarized in Table 1.

Table 1. List of study participants

\begin{tabular}{lll} 
& Hospital A & Hospital B \\
Patients and watchers & FGD (8 participants) & FGD (8 participants) \\
Doctors & FGD (7 participants) & SSI (4 interviews) \\
Nurses & FGD (7 participants) & SSI (4 interviews) \\
\hline Total participants & 22 & 20 \\
\hline
\end{tabular}

The participants, all of which must have been involved in their respective hospitals since 2011 - a year before the Sin Tax Law was passed - were recruited through personal invitations from the investigators. Informed consent was obtained and an information sheet was provided to all participants.

The research team used a semi-structured interview technique to conduct the 60-90 minute sessions. Prior to the conduct of each FGD, the research team oriented the participants about the nature of the study. The open-ended questions were developed on the basis of the research framework. Each FGD was followed by an immediate debriefing session among the facilitator and study assistant(s). In the case of Hospital B, due to the difficulty in convening participants into FGDs, SSIs were instead conducted, using the same questions (see Appendix A).

Audio recordings of the FGDs were transcribed verbatim. Transcripts were then uploaded into an NVivo 10 database, with the investigators performing open coding and virtual pile sorting. In keeping with an inductive approach to the data, no framework was used except for an attention to temporal profile of the perceived changes and the differences among the patients and healthcare workers' narratives. A group meeting was held to arrive at the final themes by consensus.

The study was given ethical approval by the University of the Philippines Manila Research Ethics Board (UPMREB 2016-382-01).

\section{FINDINGS}

The major themes that emerged from the discussions revolved around four distinct but interrelated domains: health financing, service delivery, human resources, and health facilities. In the following, we synthesized the informants' key insights according to these domains:

\section{A. Significant improvements in health financing}

Doctors, nurses, and patients alike note that the past three years have seen changes in financial coverage among inpatients that are, in the words of one doctor, "revolutionary" for health service delivery. As ES, a nurse for over 20 years, says: "Ibang iba na talaga ngayon!' ("It's very different now!") 
The doctors recall that the financial constraints of patients in the past did not just impact medical treatment it also meant that they too had to be involved in seeking financial aid. As Dr. CC puts it, residents had to function as "virtual social workers":

Before, we really had to find a way at all costs. We ourselves had to write letters of request, and call $X$ [a charity foundation based in one of the hospital's departments]. But now all you have to do is to make sure that the patients are enrolled. We have more patients but they get more funding - procedures like angiogram can be shouldered by PhilHealth. As for antibiotics, all you have to do now is fill out some forms...

The patients are very appreciative of - and sometimes even incredulous over the benefits, which are not just financial, but logistical. Patient GN recalls that in the past, they had to process various documents, but now, everything is arranged within the hospital:

We had to pay a lot even as PhilHealth members.

We ourselves go to the office; the doctor signs the documents, but we are the ones who go to the health office to process it. But now everything is here...

While unanimous in acknowledging these benefits, participants point out to aspects that can still be improved. Some point out that PhilHealth coverage remains pegged to a single institution. Dr. CP recalls a patient with pneumonia for which he had to shell out 10,000 pesos (200 USD) because, although the patient had PhilHealth coverage, it had already been used up in another hospital.

Others, while celebrating the scope of financial coverage, point to the limits of the number of people who can avail of it. In Hospital A, while the poorest of the poor enjoy no balance billing, the "near poor" or those who belong to the second lowest quintile - and even the middle class - remain vulnerable to catastrophic expenditure. On the other hand, the assistance in Hospital B is restricted to the residents of the town - a category that is sometimes "politicized" to include relatives of local officials.

\section{B. Major improvements in health service delivery}

Financial assistance led to improvements in the delivery of health services - and to an increased demand that has consequences in the two other domains: human resources and facilities. These changes were experienced differently by the different groups.

Doctors, for instance, explain that from the time a patient arrives at the emergency room, the patient's ability to pay used to be a major determinant of how they were managed - or even whether they would be admitted or not in the first place. This is because without their own financial resources, some patients would not be able to avail of the necessary treatments anyway. Dr. JD recalls that even if there were sources of funding in the past, they were insufficient to cover some illnesses:

Because of the limited resources we can allocate to so many patients, the doctor chooses who will likely to live. Isn't it painful for a doctor to have to choose who will live? But if you will consider between two patients: let's say someone who is 35 years old and a 60 year old with co-morbidities, you will more likely go for the 35 year old especially if he has the money to pay for it.

With patients' treatments now financially covered, the doctors say that this kind of informal "triage" (and consequent moral dilemmas) no longer happen - and doctors are now able to admit patients - and perform procedures and treatments regardless of the patients' ability to pay.

But the effect of increased financial coverage has not been thoroughly positive. Health care workers point out that this has increased the demand for services, sometimes to a point of overwhelming the facilities and human resources and comprising the quality of health services. Dr. PP adds the element of raised expectations that figure in this increased demand:

PhilHealth is really a big factor, because of it, more patients have been going to the hospital, sometimes beyond our capacity. Also, patients come with the expectation that they'll get admitted without having to pay anything because they're PhilHealth [members]. They really expect a lot of services... [and] they think that everything's free which is why more of them come...

Once inside the hospital the healthcare workers point to improved continuity of care, overcapacity issues notwithstanding. Citing expensive intravenous antibiotics as an example, Dr. MN recalls:

In the past, it's like the norm for someone to die of pneumonia because there's no money to buy antibiotics. Now, [that kind of situation] is unacceptable because even the full course of antibiotics - 30 to 40,000 pesos - can be shouldered by the government.

Nurses - the ones responsible for actually administering drugs - also acclaim the continuity of care. $\mathrm{RJ}$, an operating room nurse says that the lack of financial resources in the past used to stall procedures - but that no longer happens today:

It's so tough to organize a schedule at the $O R$ [operating room], but sometimes we already have the schedule, and the patients don't have the PHP 1,500 OR fee! We can plead for the OR team to wait, but sometimes the surgery gets delayed and what's sad is that they have to wait all over again. Fortunately, that's not the case anymore because the patients get covered [by PhilHealth]. 
Patients, for their part, validate the health care providers' assessment. While many of the doctors who joined the FGD studied then worked in the same hospital all their professional lives, patients have had the opportunity to experience inpatient care in other hospitals. Viewed in relation to these past hospital experiences, they are generous in their assessment. As CT, a 45-year-old barangay (village) health worker and hospital watcher, notes:

It's true. Once you're in the hospital, you don't need to go out, it will be continuous...even the laboratory. Unlike other hospitals wherein if you need laboratories you will be scrambled to other hospitals. But here, everything is here, and besides, we do not have the ability to afford other hospitals, here, almost everything is free and they really take care of the patients.

\section{Impact on health care workers}

The physicians regard the improved financial changes as generally beneficial to their experience as hospital employees. As mentioned earlier, not having to deal with patients' financial issues has allowed them to focus on their more "medical" responsibilities. Moreover, they see the ability to perform “:deal” (i.e. guideline-directed) management, made possible by the guaranteed funding, as useful towards their training.

Still, they continue to feel overwhelmed by the workload. Dr. JA, laments what she calls a "mismatch" between demand (i.e. the number of patients that seek health care) and supply (i.e. human resources and facilities):

There has been a mismatch. It created demand without increasing the supply for example there's the 'expanded health program' for the patients so everyone can go to the hospital, and various procedures can now be done, like angiogram, intubation, dialysis...but the equipment and facilities bave not been augmented so there's a mismatch of supply and demand - even in manpower. The manpower is not a tangible thing... but there's really a mismatch that's become problematic.

Aside from the increased workload, the doctors feel that they deserve to also be part of the beneficiaries of the windfall of health revenue. This is particularly a sore point to training fellows, who, while functioning in a official capacity within the hospital, do not have salaries and must come under the sponsorship of pharmaceutical companies. Dr. JD explains:

We need to voice it out to the national PhilHealth, the government plans to expand the benefits for the patients without thinking of the doctors. Fellows are not receiving a single cent from the government. They are working 24 hours a day on duty but they do not have any salary.

The nurses, for their part, also feel that the shortage of human resources has not only persisted, but got exacerbated as a result of the increased patient load. WN, a hospital nurse for over 15 years, explains:
Did anything change? A lot changed but the nursepatient ratio is still the same, 1:18. So on the nursing side, we hope plantilla (fixed) positions are added, not just nurses but also other staff like accounting, pharmacy... because the number of patients didn't just double, it tripled, because they no longer pay anything.

Held in the context of many nurses - including their own colleagues in the hospital - seeking opportunities abroad that offer far higher compensation ${ }^{9}$, the nurses feel that they too deserve additional compensation. They point out that to its credit, PhilHealth actually has a provision for healthcare workers to share in the financial incentives of hospitals - but their own hospitals have not been quick to implement it.

Patients, for their part, appreciate the services of physicians and nurses, but they also complain that some staff are ill-tempered. JO, a watcher, describes the nurses in Hospital B as "unfriendly...even if you're just asking questions they're grumpy". Patient EN captures the tension between appreciation and apprehension in her outlook towards nurses:

Actually I try to ignore the [nurses' bad attitudes] because I tell myself, because they have too many patients, there are really times when they are not approachable. They're even more intimidating than the doctors...It's okay because we are just patients, it's natural that we have to be patient and understanding...

\section{A plea for better health facilities}

Both hospitals have been in a perpetual state of undersupply - exacerbated by the increased demand necessitating resourcefulness among its workers. Our physician-informants, who did their clerkships and internships in the 2000s, recall creative ways to source supplies like syringes, IV cannulas, and foley catheters - such as making "rounds" in various wards to scour for extras - or overprescribe patients who appear to have funds to benefit others who do not. That has improved in the past few years, as CC, a hospital nurse for over 20 years, recalls:

The changes in health are really big. When Istarted in Hospital $A$ we even had to wash the surgical gauzes to reuse them. And I went through the period when disposable syringes were recycled [after sterilizing them] to a point that the needles were already blunt! Now we no longer worry about supplies.

Beyond supplies, however, our participants feel that there remains much to be desired in terms of health facilities. Dr. JD, for instance, points to the acute shortage of oxygen tanks in the medical wards:

In our Internal Medicine charity wards we have 100 admitted patients, 50 per ward. Do you know how many oxygen tanks we have? Just 16. That's how bad the situation is. Even intubated patients don't have oxygen tanks! 
While doctors see medical equipment (more monitoring equipment) in their 'wish lists', patients have pointed out non-medical facilities as sorely lacking. Both hospitals, for instance, remain non-air-conditioned, and patients and watchers complain of the unbearable heat in the wards. Patient $\mathrm{CH}$ vows to buy electric fans for the hospital if she wins the lottery:

I tell myself, if I win the lottery, I will give electric fans to the hospital. When we are in the wards you really end up fanning yourself the whole day. I will give electric fans to all the beds, I even counted the number of beds I'll need to donate electric fans too! In the OPD it is also so hot, and even in the ER. This is really what I can suggest.

\section{DISCUSSION}

\section{Implications for inpatient care}

One major disparity between the narratives of the patients and the healthcare providers is the particular kinds of facilities they complained about. While the doctors mentioned the lack of monitoring machines, the patients were looking for electric fans. This attention to facilities and equipment that figure in the 'lived experience' in the wards points to the need to consider the total hospital experience instead of just focusing on major, more "serious" equipment as far as "health facilities" are concerned.

Aside from the ventilation in both hospitals, patients also complained of the lack of clean toilets. These complaints are a reminder that patients' feedback are not always represented in top-down considerations of hospital reform, and lend support for much-overlooked patient perspectives. ${ }^{10,11}$

\section{Implications for policy}

Four years after the passage of the Sin Tax Law, the picture conveyed by the participants is that of hospitals with improved provision of - and increased demand for - health services. Invoking the illustration of the 'three dimensions of universal coverage' (Evans et al. 2011), one can say that these post-Sin Tax Law hospitals have seen improvements in at least two of them: (1) the proportion of the costs covered and (2) the actual services covered.

However, the participants also note that the above changes have not led to commensurate improvements in human resources and facilities, which are just as essential for the attainment of universal healthcare. In addition, the increased demand for health services brought about by the financial assistance has put a strain on human resources and facilities, raising what experts have called a 'problem of absorptive capacity ${ }^{12,13}$; reminding policymakers of 'side effects' of otherwise beneficial policies.

The universal healthcare bills in the Senate and the House seek to address this gap. Senate Bill 1896, for instance, mandates a "competitive compensation package" for healthcare workers. ${ }^{14}$ However, with HCWs complaining not just of poor compensation but overwork and understaffing, it remains to be seen whether these initiatives will make an impact, unless a health human resources plan is prioritized and vigorously pursued.

\section{CONCLUSION}

Our findings suggest that tertiary government hospitals have benefited from the Sin Tax Law and the financial assistance programs it has supported. The improvements we have identified support the continuation - if not expansion of legislative and executive measures towards this direction: more funds for health that should translate not only to increased financial coverage and better service delivery for patients, but also to greater support for healthcare workers - and enhanced health facilities. Finally, given how these insights may not readily be gained from traditional metrics (i.e. revenue, coverage), we recommend the use of qualitative methods to better understand how government policies and programs are affecting health service delivery, and the health care system at large.

\section{Acknowledgments}

The authors would like to acknowledge the assistance of Ms. Genoveva Nethercott and the Action for Economic Reforms, Inc. in the conduct of the research.

\section{Statement of Authorship}

All authors have approved the final version submitted.

\section{Author Disclosure}

All authors declared no conflicts of interest.

\section{Funding Source}

No funding.

\section{REFERENCES}

1. Congress of the Philippines. Republic Act 10351 (2012), "An Act Restructuring the Excise Tax on Alcohol and Tobacco Products by Amending Sections 141, 142, 145, 8, 131, and 288 of Republic Act no. 8424, Otherwise Known as the National Internal Revenue Code of 1997, As Amended by Republic Act no. 9334, and For Other Purposes". [Online] [Accessed May 29, 2017]. Available from the Philippine government website: https://www.officialgazette.gov. $\mathrm{ph} / 2012 / 12 / 19 /$ republic-act-no-10351/.

2. Department of Health (Philippines). Administrative Order No. 20100036: "The Aquino Health Agenda: Achieving Universal Health Care for All Filipinos"; 2010.

3. Department of Health (Philippines). Sin Tax Law Incremental Revenue for Health Annual Report CY 2015. Details on Expenditure of the Amounts Earmarked for Health. [Online] [Accessed May 29, 2017]. Available from the Department of Health website: http:// www.gov.ph/downloads/2015/SIN-TAX-LAW INCREMENTALREVENUE-FOR-HEALTH-CY-2015-ANNUAL-REPORT.pdf Published 2015.

4. World Health Organization (WHO). WHO Technical Manual On Tobacco Tax Administration. 2010. Geneva: World Health Organization. 
5. World Health Organization (WHO). Tobacco taxation and innovative health-care financing. 2012:16-20. Geneva: World Health Organization.

6. World Health Organization (WHO). "Sin Tax" expands health coverage in the Philippines. [Online] [Accessed May 29, 2017]. Available from the World Health Organization website: http://www. who.int/features/2015/ncd-philippines/en/ Published May 2015.

7. Glaser, B. G., \& Strauss, A. L. Discovery of grounded theory: Strategies for qualitative research. 2010. New York: Routledge.

8. Kaiser K, Bredenkamp C, Iglesias R. Sin Tax Reform in the Philippines: Transforming Public Finance, Health, and Governance for More Inclusive Development. World Bank Publications; 2016.

9. Brush BL, Sochalski, J. International nurse migration lessons from the Philippines. Policy Polit Nurs Pract 2007; 8(1):37-46.

\section{APPENDIX: GUIDE QUESTIONS}

\section{Guide questions for patients}

\section{A. Experiences with the healthcare system}

1. How long have you been coming to this hospital? Tell us about your experiences

2. Why did you choose this hospital?

3. What problems did you face here? (Ask them to enumerate challenges i.e. financial problems, lack of human resources, communication with health care workers, quality of health care, etc.)

B. Interactions with healthcare workers and hospital staff

1. Who are the health care workers that you interacted with, and how were your experiences with them? (Ask them to provide overall feedback on health care workers including their attitudes, service, perceived competence, etc.)

2. Have you ever asked for financial aid? What was the process? Who did you approach for that?

3. How was the process of payment and getting discharged from the hospital (Ask them about the more pragmatic aspects of health care and their dealings with hospital staff that deal with these aspects)

\section{Perceptions of change}

1. What changes in the hospital have you noticed from the time you started coming here to the present? (Open ended, but refer back to discussion points "a" and "b" to enumerate various domains of health care. Ask them to add temporality to problems and challenges encountered.)

2. We are interested in particular in the year 2014 until the present. Are there changes that you noticed particularly during this period? (Use this leading question only if not enough information was gathered using the previous one)

3. What are the improvements that you want to see in the hospital?
10. Van der Geest S, Finkler, K. Hospital ethnography: introduction. Soc Sci Med 2004; 59(10):1995-2001.

11. Cain CH, Neuwirth E, Bellows J, Zuber C, Green, J. Patient experiences of transitioning from hospital to home: an ethnographic quality improvement project. J Hosp Med 2012; 7(5): 382-7.

12. Evans, DB, Hsu J, Boerma R. Universal health coverage and universal access. Bull World Health Organ. 2013; 91.8: 546.

13. World Health Organization (WHO). Earmarked tobacco taxes: lessons learnt from nine countries. 2012:56-59

14. Senate of the Philippines (17th Congress). Senate Bill 1986. "The Universal Health Care for All Filipinos Act”. 2018.

\section{Guide questions for healthcare workers}

\section{A. Experiences with the healthcare system}

1. How long have you been working in this hospital? Tell us about your experiences

2. Why did you choose this hospital?

3. What problems did you face here? (Ask them to enumerate challenges i.e. lack of equipment, shortage in human resources, labor issues, etc.)

\section{B. Perceptions of change}

1. What changes in the hospital have you noticed from the time you started working here to the present? (Open ended, but refer back to discussion points "a" and " $\mathrm{b}$ " to enumerate various domains of health care. Ask them to add temporality to problems and challenges encountered.)

2. We are interested in particular in the year 2014 until the present. Are there changes that you noticed particular during this period? (Use this leading question only if not enough information was gathered using the previous one)

3. What improvements do you want to see in the hospital? 